\title{
The effectiveness of psychosocial interventions for anxiety in children and adolescents with autism spectrum disorder: a systematic review and meta-analysis
}

\author{
Ance Kreslins, Ashley E. Robertson ${ }^{*}$ and Craig Melville
}

\begin{abstract}
Anxiety is a common problem in children and adolescents with autism spectrum disorder (ASD). This meta-analysis aimed to systematically evaluate the evidence for the use of psychosocial interventions to manage anxiety in this population. Cognitive behavioural therapy (CBT) was the primary intervention modality studied. A comprehensive systematic search and study selection process was conducted. Separate statistical analyses were carried out for clinician-, parent-, and self-reported outcome measures. Sensitivity analyses were conducted by removing any outlying studies and any studies that did not use a CBT intervention. A subgroup analysis was performed to compare individual and group delivery of treatment. Ten randomised control trials involving a total of 470 participants were included. The overall SMD was $d=1.05(95 \% \mathrm{Cl} 0.45,1.65 ; z=3.45, p=0.0006)$ for clinician- reported outcome measures; $d=1.00(95 \% \mathrm{Cl} 0.21,1.80 ; z=2.47, p=0.01)$ for parent-reported outcome measures; and $d=0.65(95 \% \mathrm{Cl}-0.10$, $1.07 ; z=1.63, p=0.10$ ) for self-reported outcome measures. Clinician- and parent-reported outcome measures showed that psychosocial interventions were superior to waitlist and treatment-as-usual control conditions at post-treatment. However, the results of self-reported outcome measures failed to reach significance. The sensitivity analyses did not significantly change these results and the subgroup analysis indicated that individual treatment was more effective than group treatment. The main limitations of this review were the small number of included studies as well as the clinical and methodological variability between studies.
\end{abstract}

Keywords: Meta-analysis, Autism spectrum disorder/ASD, Anxiety, Child, Adolescent, Psychosocial intervention, Cognitive behavioural therapy/CBT

\section{Introduction}

Autism Spectrum Disorder (ASD) is a neurodevelopmental disorder characterised by a triad of symptoms - deficits in social communication, impaired social interaction and lack of flexibility of thought and behaviour. These features appear in early childhood and endure across the lifespan [1]. ASD is an umbrella term introduced in the DSM-5 to define a continuum of symptoms, formerly classified as separate autistic disorders. These disorders included Autistic disorder, Asperger syndrome (AS), and pervasive developmental disorder not otherwise specified

\footnotetext{
* Correspondence: ashleyerobertson@icloud.com Institute of Health and Wellbeing, University of Glasgow, 1st Floor Admin Building Gartnavel Royal Hospital, 1055 Great Western Road, Glasgow, G12 $\mathrm{OXH}$, Scotland
}

(c) 2015 Kreslins et al. This is an Open Access article distributed under the terms of the Creative Commons Attribution License (http://creativecommons.org/licenses/by/4.0), which permits unrestricted use, distribution, and reproduction in any medium, provided the original work is properly credited. The Creative Commons Public Domain Dedication waiver (http:// creativecommons.org/publicdomain/zero/1.0/) applies to the data made available in this article, unless otherwise stated.
(PDD-NOS) [2]. ASD has a prevalence of $1.16 \%$ in the general population [3].

Around $70 \%$ of children with ASD also experience psychiatric comorbidity [4], with one of the most common being anxiety [5]. Although anxiety in ASD is present across the whole spectrum of the disorder, the presentation seems to be affected by individual factors, such as age, degree of social impairment and level of cognitive functioning [6]. Prevalence rates of anxiety disorders in typically developing children range between 2 and $27 \%$ [7], whereas rates of 11-84 \% have been reported in the children with ASD [6]. However, it should be noted that rates vary substantially between studies due to varying sampling methods and anxiety assessments [6]. The most commonly reported anxiety disorders in the paediatric 
ASD population are specific phobia (30\%), obsessive compulsive disorder (OCD) (17 \%) and social anxiety (17\%) [8]. This distribution is similar to that seen in typically developing children, apart from OCD, which is more common in ASD [8, 9].

Due to a unique interaction between anxiety and core ASD symptomology, the manifestation of anxiety in children and adolescents with ASD differs in several ways from anxiety seen in typically developing youth [10]. Anxiety in ASD is associated with more behavioural problems, such as social avoidance, repetitive behaviours and aggression [6, 11]. These maladaptive behaviours may be difficult to differentiate from symptoms of ASD $[6,9,12]$ resulting in anxiety being underreported in this population $[13,14]$. As a result of the significant diagnostic overlap between anxiety disorders and core ASD symptoms, it has been discussed whether anxiety should be considered as part of ASD $[8,11]$. However, ASD may simply predispose to anxiety [9] since individuals with ASD struggle to manage perceived threatening external stimuli due to deficits in executive functioning, inherent difficulties understanding emotions, and problems with social and communication skills $[9,11,15]$. Furthermore, anxiety levels in ASD youth may be affected by an increased or decreased sensitivity to sensory stimuli and motor clumsiness [15].

Cognitive behavioural therapy (CBT) has been shown to be effective in treating anxiety in typically developing children and adolescents [16]. Furthermore, CBT can be modified in a number of ways to make this treatment modality more suitable for the ASD population [15]. Some of the issues that may affect the delivery of CBT in ASD youth are difficulties responding to social cues and engaging in reciprocal exchanges [17], as well as reduced verbal skills and difficulties processing figurative meaning [15]. In addition, ASD youth may have difficulties understanding and expressing emotions, and may have reduced Theory of Mind (ToM) abilities, i.e. the ability to identify their own and other individuals' thoughts and emotions $[18,19]$. It is essential that therapists have insight into the difficulties people with ASD may face in order to develop a therapeutic content, setting and relationship that is tailored specifically for the needs of this population [15].

The majority of research carried out to ascertain the effectiveness of psychosocial interventions in the ASD population is biased toward the high functioning end of the spectrum [6]. This may be due to the logistical and ethical issues that may arise when working with more severely impaired individuals, including difficulties with communication, giving informed consent, attending to tasks and following instructions. The exclusion of youths on the spectrum with cognitive limitations creates problems with generalising results to the Autism Spectrum as a whole. This needs to be taken into account when interpreting study results. In the UK, individual or group CBT is therefore recommended to manage anxiety in children and young people with ASD if they have the necessary verbal and cognitive abilities [4].

The literature addressing treatment options for anxiety in ASD youth has been constantly growing over the past decade. At present, a considerable number of studies investigating psychosocial interventions for anxiety in children and adolescents with ASD have been conducted. Furthermore, comparable outcome measures have been used in these studies, making it possible to perform a meta-analysis. The primary treatment modality studied in this meta-analysis was CBT, but it was considered important to also include other types of psychosocial modalities, such as social skills interventions, since components of these may be used to optimise content and delivery of any anxiety management intervention aimed at ASD youth.

The objective of this meta-analysis was to systematically review the evidence for the use of psychosocial interventions to manage anxiety in children and adolescents with ASD.

\section{Methods}

\section{Information sources and search strategy}

This review was designed in accordance with the PRISMA guidelines [20]. Two independent researchers identified studies by searching electronic databases and manually finding suitable published studies. The following databases were searched: Web of Science, PsychINFO, Embase, Medline and Cochrane Database of Systematic Reviews (Cochrane Library). The search strategy included terms such as ASD, auti*, child*, anxi*, psychotherap* and cognitive behavi* therap*. It was limited to the title and abstract or the topic, depending on the availability of search options within each database. In addition, the search was limited to journals in English with a publication year 2000-2013 due to practical reasons and the fact that, to our knowledge, there were no studies published prior to 2000 that met our inclusion criteria. The final search was run on the $13^{\text {th }}$ of November 2013.

\section{Eligibility criteria and study selection}

Studies were included if they met the following criteria: a) the study was published in English and between the years 2000-2013; b) the study was a randomised control trial (RCT); c) the patient population was children and/or adolescents (age $0-18$ years) with a primary diagnosis of ASD and clinically significant anxiety symptoms; and d) at least one outcome measure was a standardised continuous measure of anxiety (parent-, clinician-, or self-reported). Studies were screened based on the title and abstract. The 
final selection of studies was performed using tools provided in the Cochrane Collaboration Handbook [21].

\section{Selection of outcome measures}

Outcome measures were selected depending on their validity and frequency of use. Judgement of the validity of anxiety measures in the ASD population was based on two recently published, methodologically rigorous reviews $[10,11]$. The frequency of use was considered important to ensure maximum possible comparability between study results. The selected clinician-reported outcome measures were The Anxiety Disorders Interview Schedule - Child /Parent version (ADIS-C/P) [22], The Pediatric Anxiety Rating Scale (PARS) [23] and The Childhood Anxiety Sensitivity Index - Anxiety (CASI-Anx) [24]. Spence Children's Anxiety Scale - Parent version (SCAS-P) [25] and Multidimensional Anxiety Scale for Children - Parent version (MASC-P) [26] were used as parent-reported outcome measures. Children's Anxiety Scale - Child version (SCAS-C) [25], Multidimensional Anxiety Scale for Children - Child version (MASC-C) [26], Revised Children's Manifest Anxiety Scale (RCMAS) [27] and Social Interaction Anxiety Scale (SIAS) [28] were chosen as selfreported outcome measures.

If a study used two of the selected outcome measures, one of the measures was chosen for the analysis. Storch et al. [29] reported both ADIS-C/P and PARS scores. Although both measures are considered to be equally well validated [11], PARS was selected for the purpose of this review since the required ADIS-C/P scores were not available. Chalfant et al. [30] included both SCAS-C and MASC-C. The superiority of the SCAS-C or the MASC$C$ in terms of validity was not clear $[10,11]$. Therefore, SCAS-C was chosen based on its frequency of use across the reviewed studies. Although RCMAS and SIAS had not been validated for use in the ASD population [10,11], they were used when studies lacked results from more validated outcome measures. Storch et al. [29] did not report total RCMAS scores. Therefore, an average of the subscale scores was used.

\section{Data collection process and risk of bias within studies}

Data extraction and risk of bias assessment was performed according to the Cochrane Collaboration Guidelines [21]. The first author conducted the systematic search and the second author verified inclusion/exclusion of a subset of studies. Both authors independently screened the originally selected studies and agreed on which studies should be selected for the review. Data extraction and risk of bias assessment were conducted independently by the first and second author. Any discrepancies between the authors' ratings were arbitrated by an independent party. Risk of bias within studies was rated as high risk (bias that reduces reliability of results), low risk (bias that is unlikely to alter results) or unclear (bias that raises doubt about reliability of results/insufficient information provided to make judgment). Only methodological strengths and weaknesses that were relevant for the results of this meta-analysis were considered when assessing the risk of bias.

Selection bias was assessed based on adequate description of random sequence generation and concealment of treatment group allocation. Due to the nature of the interventions, blinding of participants and personnel was not feasible in any of the included studies. Therefore, all studies had a high risk of performance bias. Similarly, detection bias was high for parent- and self-reported outcome measures in all studies since blinding of these measures was not viable. The studies that blinded clinician-reported outcomes were scored as having a low risk of detection bias. Attrition bias was assessed by examining the reporting of withdrawals and drop-outs. Outcome data were considered complete if there were no missing pre- or post-treatment data, or if the study authors had carried out an intent-to-treat analysis. Protocols were not available for any of the eleven studies. Reporting bias was therefore evaluated purely based on evidence of selective outcome reporting provided in the study reports. No studies were excluded based on the risk of bias assessment.

\section{Summary measures and synthesis of results}

Separate statistical analyses were carried out for clinician-, parent-, and self-reported outcome measures. Standardised mean difference (SMD) was used as the summary estimate of treatment effect. This summary statistic was chosen because the analysis was performed on a variety of continuous outcome measures. SMDs of $-0.2,-0.5$ and -0.8 were deemed to be indicative of small, moderate and large effects respectively [31]. According to the Cochrane Collaboration Guidelines [21], the SMD can be calculated using means and standard deviations either of final measurements or of changes from baseline. Standard deviations of changes were not reported in any of the included studies. Therefore, SMD estimates were calculated based on the post-treatment scores and standard deviations provided in each study report. No adjustments of the scores were required since the direction of the scales was the same for all outcome measures. The statistical significance level was set at $\mathrm{p}<0.05$. Forest plots were used to illustrate results from individual studies. In the case of multiple treatment arms, such as in the study conducted by Sung et al. [32], the average score of both intervention groups was compared to the control group score.

Higgin's $I^{2}$ [33] test was used to describe in percentage the impact of heterogeneity on the effect estimates. It was chosen over Cochrane's Q Test since the latter has low power when there are few studies [34]. An $\mathrm{I}^{2}$ of less 
than $30 \%$ was considered to indicate mild heterogeneity and one substantially higher than $50 \%$ was thought to reflect substantial heterogeneity [33]. Considerable statistical heterogeneity was expected both due to clinical diversity (variability in the participants, interventions and outcomes) and methodological diversity (variability in study design and risk of bias). As a result, a random-effects model was chosen to estimate intervention effect (DerSimonian and Laird approach) [34]. All statistical analyses were conducted using Review Manager 5.1 software [35].

Follow-up data was examined to determine whether the effects of the treatment were maintained after the end of the intervention. When examining follow-up results, sufficient data was not available to conduct a statistical analysis. It was therefore assumed that the statistical analyses conducted in the individual studies were correct.

\section{Additional analyses}

Due to the small number of studies in each review category, publication bias could not be assessed formally by using a funnel plot or statistical test [31,36]. After discussion between the study authors, it was decided that studies would be considered outliers if the SMD was 3 times greater than the next highest SMD in that category. To analyse the effect outlying studies had on the summary estimates, a sensitivity analysis was conducted by removing any outlying studies in each category. Since the eligibility of non-CBT interventions for this metaanalysis was debatable, a sensitivity analysis was also performed by removing any studies that did not use a CBT intervention.

Due to the relatively limited research addressing psychosocial treatment options for anxiety in children and adolescents with ASD, it was deemed appropriate to include studies that used both individual and group interventions. To compare the effectiveness of these delivery methods, a subgroup analysis was conducted by comparing the confidence intervals of the summary estimates in the two subgroups (individual $+/$ - group therapy versus group therapy only). No or minimal overlap between the confidence intervals was considered indicative of statistical significance. Subgroup analyses were only performed on outcome measures if the overall summary estimate was significant. The effects of other treatment moderators, such as age, anxiety diagnosis, parental involvement and types of intervention modifications, could not be performed due to difficulty obtaining sufficiently comparable data from the study reports.

\section{Results}

\section{Study selection}

The search of the databases yielded 1847 results, 575 of which were duplicates. One paper was added which had not yet been published at the time of the search [37].
1272 records were screened based on the title and abstract, 1242 of which were excluded. An additional three were excluded due to a lack of full-text availability. Twenty-seven full-text papers were assessed for eligibility. A total of ten studies met the inclusion criteria for this review. A flow diagram of the study selection is shown in Fig. 1.

\section{Study characteristics}

A total of 470 (393 male, 72 female and five not reported) participants aged 7-17 years were included. Nine studies used a modified CBT intervention [29, 30,32, 37-42] and Schohl et al. used a social skills intervention [43]. Chalfant et al., McConachie et al., Schohl et al., Sofronoff et al., and Sung et al. delivered the intervention in a group format (group sizes varying between 3 and 10 participants/group) [30, 32, 37, 40, 43]. McNally Keehn et al., Storch et al., and Wood et al. used individual therapy [29, 38, 42]. Reaven et al. and White et al. used a combination of individual and group therapy $[39,41]$. The duration of the interventions varied between 6 and 16 sessions and the length of each session was 60 to $120 \mathrm{~min}$.

Sung et al. [40] had an active control group in the form of a social recreational group program. The rest of the studies had waitlist or treatment-as-usual (WL/TAU) control conditions $[29,30,32,37,38,40-43]$. In the majority of the included studies, participants randomised to the intervention, active control and/or WL/TAU conditions were permitted to initiate and/or continue receiving pharmacological-, psychoeducational- and/or other interventions during the study period [29, 30, 37-41]. Schohl et al., Sofronoff et al., and Wood et al. provided no information about the additional interventions received by participants. Conclusions about the extent to which these supplementary interventions may have affected the treatment effect could not be made due to insufficient and inconsistent provision of information across studies about the uptake of additional services.

The study authors established the ASD diagnoses either by using The Autism Diagnostic Observation Schedule (ADOS) [44] or by relying on a diagnosis made by a paediatrician, psychiatrist or clinical psychologist. Since the psychosocial interventions used in all ten studies required verbal communication skills, it can be assumed that a certain level of language and cognitive ability was necessary for participation in all included studies. In six studies, the presence of an anxiety disorder was required for inclusion [29, 30, 37, 38, 41, 42]. In all of these studies, the diagnosis was determined using ADIS [21]. The rest of the studies relied on parents providing an accurate report of clinically significant anxiety symptoms or social difficulties. A summary of study characteristics can be found in Table 1. 


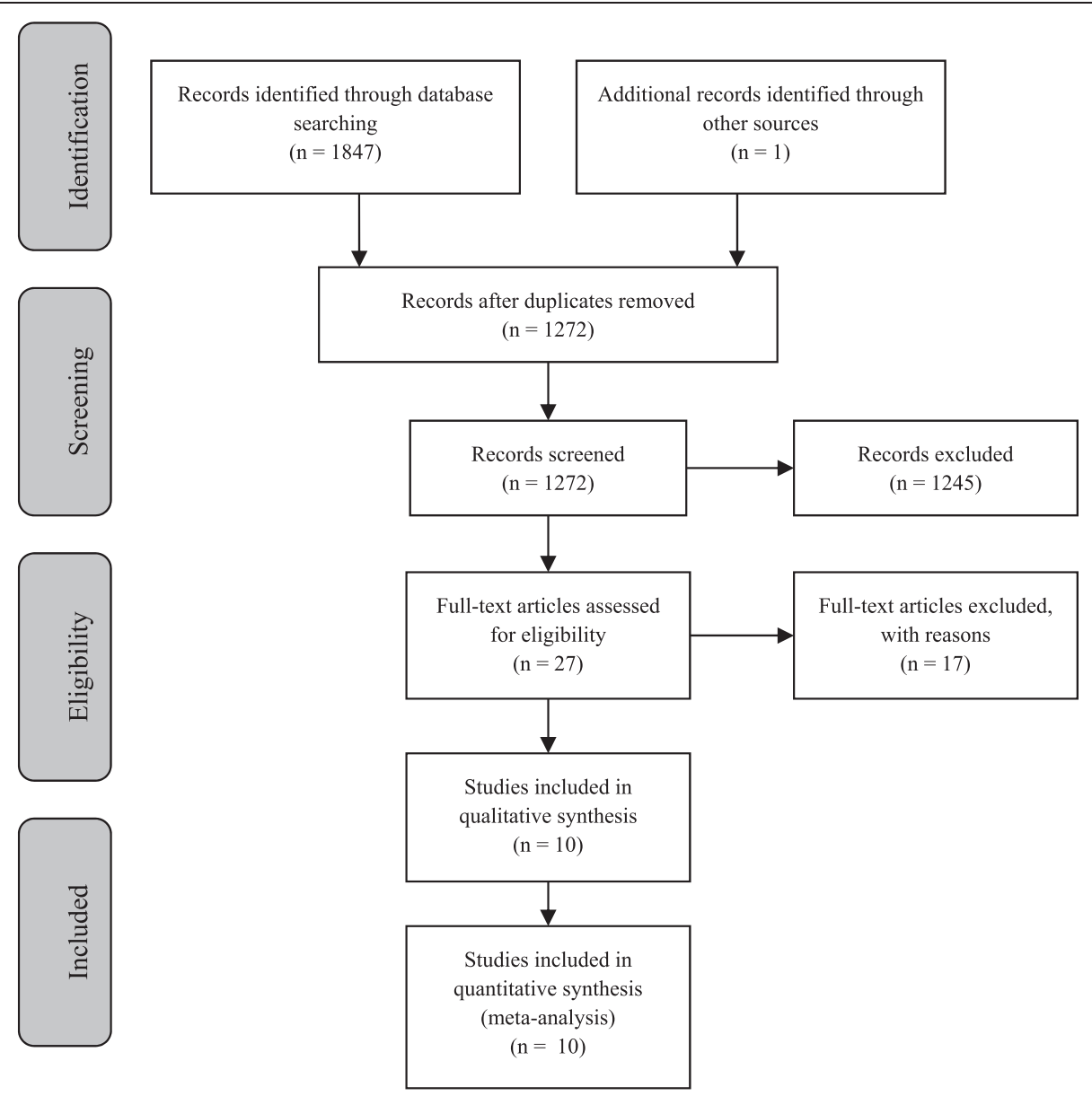

Fig. 1 PRISMA flow diagram of study selection

\section{Risk of bias within studies}

\section{Selection bias - random sequence generation and allocation concealment}

Six of the included studies performed adequate random sequence generation, either manually or generated by a computer [29, 37, 39-42]. Chalfant et al, Sofronoff et al, McNally Keehn et al, and Schohl et al. provided insufficient information about the randomisation process to determine the extent to which this may have affected the bias of these studies [30, 32, 38, 43]. McConachie et al. performed satisfactory and complete allocation concealment [37]. In contrast, Chalfant et al. and Sung et al. did not perform adequate allocation concealment [30, 40]. The remainder of the included studies indicated that allocation concealment was implemented, but did not provide sufficient information about the method of concealment [29, 32, 38, 39, 41-43].

\section{Performance and detection bias - blinding of participants,} personnel and outcome assessment

As previously stated, blinding of participants and personnel was not possible in any of the included studies. Furthermore, blinding of parent- and self-reported outcome measures was not feasible. In the studies conducted by Storch et al., McConachie et al., McNally Keehn et al., White et al., and Wood et al., clinicians rating the ADIS or PARS were blind to treatment allocation and these outcome measures were therefore considered to have a low risk of detection bias [29, 37, 38, 41, 42].

\section{Attrition and reporting bias - incomplete outcome data and selective outcome reporting}

Reaven et al. and Schohl et al. were thought to have a high risk of attrition bias since missing data was removed from the study analysis $[39,43]$. The remainder of the included studies were deemed to have complete outcome data $[29,30,32,37,38,40-42]$. There was no evidence of selective outcome reporting in any of the included studies [29, 30, 32, 37-43].

\section{Clinician reported outcome measures}

Six studies involving a total of 208 patients (102 in the treatment condition and 106 in the control condition) reported a clinician-reported outcome measure. All studies 
Table 1 A summary of study characteristics

\begin{tabular}{|c|c|c|c|c|c|c|c|c|c|}
\hline Source & Population & No. of participants & Age range $^{a}$ & Intervention & Delivery & $\begin{array}{l}\text { Parental/caregiver } \\
\text { involvement }\end{array}$ & Comparison & $\begin{array}{l}\text { Outcome } \\
\text { measures }\end{array}$ & SMD \\
\hline \multirow{2}{*}{$\begin{array}{l}\text { Chalfant } \\
\text { et al., } 2007 \\
\text { [30] }\end{array}$} & \multirow{2}{*}{$\begin{array}{l}\text { Children with HFAD or } \\
\text { Asperger disorder and a } \\
\text { primary anxiety disorder. }\end{array}$} & \multirow{2}{*}{$\begin{array}{l}47 \text { ( } 35 \text { male, } 12 \\
\text { female) }\end{array}$} & \multirow{2}{*}{$\begin{array}{l}\text { 8-13 years (mean } \\
10.8, \text { SD 1.35) }\end{array}$} & \multirow[t]{2}{*}{ CBT $(n=28)$} & \multirow{2}{*}{$\begin{array}{l}\text { Group sessions } \\
\text { (6-8 children/group). }\end{array}$} & \multirow[t]{2}{*}{-} & \multirow[t]{2}{*}{$\mathrm{WL} / \mathrm{TAU}(\mathrm{n}=19)$} & SCAS-P & 4.27 \\
\hline & & & & & & & & SCAS-C & 2.64 \\
\hline \multirow{3}{*}{$\begin{array}{l}\text { McConachie } \\
\text { et al., } 2013 \\
\text { [37] }\end{array}$} & \multirow{3}{*}{$\begin{array}{l}\text { Children with ASD and } \\
\text { at least one anxiety } \\
\text { disorder. }\end{array}$} & \multirow{3}{*}{$\begin{array}{l}32 \text { ( } 28 \text { male, } \\
4 \text { female) }\end{array}$} & \multirow{3}{*}{$\begin{array}{l}\text { 9-13 years } \\
\text { and } 11 \text { months }\end{array}$} & \multirow[t]{3}{*}{ CBT $(n=17)$} & \multirow{3}{*}{$\begin{array}{l}\text { Group sessions } \\
\text { (no./group not reported). }\end{array}$} & \multirow{3}{*}{$\begin{array}{l}\text { Separate parallel } \\
\text { groups for parents. }\end{array}$} & \multirow[t]{3}{*}{ WL/TAU $(n=15)$} & ADIS-C & 0.43 \\
\hline & & & & & & & & SCAS-P & 0.20 \\
\hline & & & & & & & & SCAS-C & 0.04 \\
\hline \multirow{3}{*}{$\begin{array}{l}\text { McNally } \\
\text { Keehn et al., } \\
2013 \text { [38] }\end{array}$} & \multirow{3}{*}{$\begin{array}{l}\text { Children with an ASD } \\
\text { and at least one primary } \\
\text { anxiety disorder of SAD, } \\
\text { GAD or SoP. }\end{array}$} & \multirow{3}{*}{$\begin{array}{l}22 \text { (21 male, } \\
1 \text { female) }\end{array}$} & \multirow{3}{*}{$\begin{array}{l}8-14 \text { years (mean } \\
11.26, \text { SD } 1.53 \text { ) }\end{array}$} & \multirow[t]{3}{*}{ CBT $(n=12)$} & \multirow[t]{3}{*}{ Individual sessions. } & \multirow[t]{3}{*}{-} & \multirow[t]{3}{*}{$\mathrm{WL} / \mathrm{TAU}(\mathrm{n}=10)$} & ADIS-P & 1.35 \\
\hline & & & & & & & & SCAS-P & 0.91 \\
\hline & & & & & & & & SCAS-C & 0.47 \\
\hline $\begin{array}{l}\text { Reaven } \\
\text { et al., } 2012 \\
\text { [39] }\end{array}$ & $\begin{array}{l}\text { Children with ASD and } \\
\text { clinically significant } \\
\text { anxiety symptoms. }\end{array}$ & $\begin{array}{l}50 \text { ( } 48 \text { male, } \\
2 \text { female) }\end{array}$ & $\begin{array}{l}7-14 \text { years (mean } \\
10.4 \text { years, SD 1.7) }\end{array}$ & CBT $(n=24)$ & $\begin{array}{l}\text { Children only group sessions } \\
\text { (3-6 children/ group), parent } \\
\text { and children sessions, parent- } \\
\text { child dyad sessions. }\end{array}$ & $\begin{array}{l}\text { Parent and children group } \\
\text { sessions, parent only and } \\
\text { child only group sessions, } \\
\text { parent-child dyad sessions. }\end{array}$ & WL/TAU $(n=26)$ & ADIS-P & 0.60 \\
\hline $\begin{array}{l}\text { Schohl et al., } \\
2013 \text { [43] }\end{array}$ & $\begin{array}{l}\text { Adolescents with ASD } \\
\text { and social problems. }\end{array}$ & $\begin{array}{l}63 \text { (47 male, } 11 \text { female, } \\
5 \text { not specified) }\end{array}$ & $\begin{array}{l}11-16 \text { years (mean } \\
13.65 \text { years, SD 1.50) }\end{array}$ & $\begin{array}{l}\text { Social skills } \\
\text { intervention } \\
(n=34)\end{array}$ & $\begin{array}{l}\text { Group sessions ( } \leq 10 \\
\text { adolescents per group). }\end{array}$ & $\begin{array}{l}\text { Separate parallel groups } \\
\text { for parents. }\end{array}$ & WL/TAU $(n=29)$ & SIAS & 0.16 \\
\hline $\begin{array}{l}\text { Sofronoff } \\
\text { et al., } 2005 \\
\text { [32] }\end{array}$ & $\begin{array}{l}\text { Children with AS and } \\
\text { anxiety symptoms. }\end{array}$ & $\begin{array}{l}71 \text { ( } 62 \text { male, } \\
9 \text { female) }\end{array}$ & 10-12 years & $\begin{array}{l}\text { CBT Child only } \\
(n=23) . \text { CBT } \\
\text { Child }+ \text { parent } \\
(n=25)\end{array}$ & $\begin{array}{l}\text { Group sessions ( } 3 \text { children/ } \\
\text { group, allocated by age and } \\
\text { sex, with girls grouped } \\
\text { together) }\end{array}$ & $\begin{array}{l}\text { Separate parallel groups } \\
\text { for parents ( } 12-13 \text { parents/ } \\
\text { group) }\end{array}$ & $W L / T A U(n=23)$ & SCAS-P & 0.09 \\
\hline \multirow{3}{*}{$\begin{array}{l}\text { Storch et al., } \\
2013 \text { [29] }\end{array}$} & \multirow{3}{*}{$\begin{array}{l}\text { Children with ASD and } \\
\text { a primary diagnosis of } \\
\text { SAD, GAD or OCD. }\end{array}$} & \multirow{3}{*}{$\begin{array}{l}45 \text { ( } 36 \text { male, } \\
9 \text { female) }\end{array}$} & \multirow[t]{3}{*}{ 7-11 years } & \multirow[t]{3}{*}{ CBT $(n=24)$} & \multirow[t]{3}{*}{ Individual sessions. } & \multirow{3}{*}{$\begin{array}{l}\text { Separate parallel parent } \\
\text { sessions +/- parental } \\
\text { involvement in child- } \\
\text { focused components. }\end{array}$} & \multirow[t]{3}{*}{ WL/TAU $(n=21)$} & PARS & 1.38 \\
\hline & & & & & & & & MASC & 0.48 \\
\hline & & & & & & & & RCMAS & 0.26 \\
\hline $\begin{array}{l}\text { Sung et al., } \\
2011 \text { [40] }\end{array}$ & $\begin{array}{l}\text { Children and } \\
\text { adolescents with ASD } \\
\text { and anxiety-related } \\
\text { issues. }\end{array}$ & $\begin{array}{l}70 \text { ( } 66 \text { male, } \\
4 \text { female) }\end{array}$ & $9-16$ years & CBT $(n=36)$ & $\begin{array}{l}\text { Group sessions } \\
\text { (3-4 participants/ group). }\end{array}$ & - & $\begin{array}{l}\text { Social recreational } \\
\text { group program }(n=34) \text {. }\end{array}$ & SCAS-C & 0.07 \\
\hline \multirow{2}{*}{$\begin{array}{l}\text { White et al., } \\
2013 \text { [41] }\end{array}$} & \multirow{2}{*}{$\begin{array}{l}\text { Children with ASD and } \\
\text { at least one of SoP, GAD, } \\
\text { SP, or SAD. }\end{array}$} & 30 (23 male, & 12-17 years (mean & CBT $(n=15)$ & Individual and group & Parent education and & $\mathrm{WL} / \mathrm{TAU}(\mathrm{n}=15)$ & PARS & 0.32 \\
\hline & & & & & $\begin{array}{l}\text { sessions (no./group } \\
\text { not reported). }\end{array}$ & & & CASI Anx & 0.37 \\
\hline Wood et al., & Children with ASD and & 40 (27 male, 13 & 7-11 years, mean & CBT $(n=17)$ & Individual sessions. & 60 min of each session & $\mathrm{WL} / T A \cup(n=23)$ & ADIS-C/P & 2.47 \\
\hline 2009 [42] & SAD, SoP or OCD. & temale) & 9.20, SD 1.49 & & & spent with parents/tamily. & & MASC-P & 1.21 \\
\hline & & & & & & & & MASC-C & -0.03 \\
\hline
\end{tabular}

$S M D$ Standardised mean difference, HFAD High Functioning Autistic Disorder, SAD Separation anxiety disorder, GAD Generalised anxiety disorder, SoP Social phobia, SP Specific phobia, OCD Obsessive Compulsive Disorder, CBT Cognitive behavioural therapy, WL/TAU Wait list/Treatment as usual, SCAS-C/P The Spence Children's Anxiety Scale - Child/Parent, ADIS C/P The anxiety Disorders Interview Schedule - Child/Parent, SIAS The social Interaction Anxiety Scale, PARS The Pediatric Anxiety Rating Scale, MASC The Multidimensional Anxiety Scale for Children, RCMAS The Revised Children's Manifest Anxiety Scale, CASI-Anx Child and Adolescent Symptom Inventory-4 ASD

${ }^{\mathrm{a}}$ Mean and SD reported when data was available 
reported greater improvements post-treatment in the intervention condition compared to the control condition. The overall SMD was $d=1.05$ (95 \% CI 0.45, 1.65; $\mathrm{z}=3.45, \mathrm{p}=0.0006$ ) which can be considered a large effect. Based on these measures, the anxiety levels in the intervention groups were significantly lower than those seen in the WL/TAU groups at post-treatment. Considerable heterogeneity across the studies was detected $\left(\mathrm{I}^{2}=74 \%\right)$. A forest plot illustrating these results is included as Fig. 2.

\section{Parent reported outcome measures}

Seven studies reported at least one of the selected parentreported outcome measures. These studies involved 283 participants (158 in the experimental condition and 125 in the control condition). The overall SMD was $d=1.00$ (95\% CI 0.21, 1.80; $\mathrm{z}=2.47, \mathrm{p}=0.01$ ) and the difference between the intervention and control conditions at posttreatment reached significance. There was significant heterogeneity across the included studies $\left(\mathrm{I}^{2}=89 \%\right)$. A forest plot illustrating these results is included as Fig. 3. The SMD reported by Chalfant et al. [30] was considered an outlier since it was substantially higher than the ones reported in the other studies. Once this outlier was removed, the overall SMD decreased to 0.48 (95\% CI 0.14, $0.82 ; \mathrm{z}=2.80, \mathrm{p}=0.005)$. Although the summary estimate decreased following removal of the outlying study, the treatment effect remained significant.

\section{Self-reported outcome measures}

Self-reported outcome data from 297 participants (152 in the intervention condition and 145 in the control condition) across seven studies was reported. The overall SMD was $\mathrm{d}=0.649$ (95\% CI $-0.10,1.07 ; \mathrm{z}=1.63, \mathrm{p}=0.10)$ with no significant difference between the experimental and control conditions at post-treatment. There were high levels of heterogeneity across the studies $\left(\mathrm{I}^{2}=83 \%\right)$. A forest plot illustrating these results is included as Fig. 4. Once more, the SMD reported by Chalfant et al. [30] was an outlier and removal of this study reduced the overall SMD to 0.14 ( $95 \% \mathrm{CI}-0.11,0.39 ; \mathrm{z}=2.80, \mathrm{p}=0.005)$. A sensitivity analysis was carried out by removing Schohl et al. [43], the only study that did not use a CBT intervention. This changed the overall SMD to 0.55 (95\% CI -0.16, 1.27; $\mathrm{z}=1.51$, $\mathrm{p}=0.13)$ and the difference between intervention and control conditions at post-treatment remained insignificant.

\section{Group versus individual intervention}

A subgroup analysis comparing individual +/- group therapy versus group therapy only was conducted for clinician- and parent-reported outcome measures. For clinician-reported outcome measures, the summary estimate for studies that used individual $+/$ - group therapy was 1.70 (95 \% CI 1.01, 2.40; $\mathrm{z}=3.37, \mathrm{p}=0.0007)$. This can be compared to the summary estimate for studies that used group therapy only which was 0.47 (95\% CI 0.08 , $0.86 ; \mathrm{z}=2.36, \mathrm{p}=0.02$ ). Although the difference between experimental and control conditions at post-treatment were significant for both individual $+/$ - group therapy and group therapy only, the confidence intervals for the two subgroups did not overlap. This indicates that, according to clinician-reported outcome measures, individual therapy as part of the intervention improved its effectiveness.

For parent-reported outcome measures, the summary estimate was 0.81 (95\% CI 0.36, 1.26; $\mathrm{z}=3.56, \mathrm{p}=0.0004$ ) for studies that used individual $+/$ - group therapy and $1.17(95 \%$ CI $-0.28,2.62 ; \mathrm{z}=1.58, \mathrm{p}=0.11)$ for those that used group therapy only. The confidence intervals clearly overlapped and it can therefore be concluded that, for parent-reported outcome measures, individual therapy components did not significantly increase the effectiveness of the interventions. However, it should be noted that the summary estimate for the studies that used individual +/group therapy reached significance and for those that used group therapy only failed to do so. This implies that individual therapy modules may be necessary to make therapy beneficial.

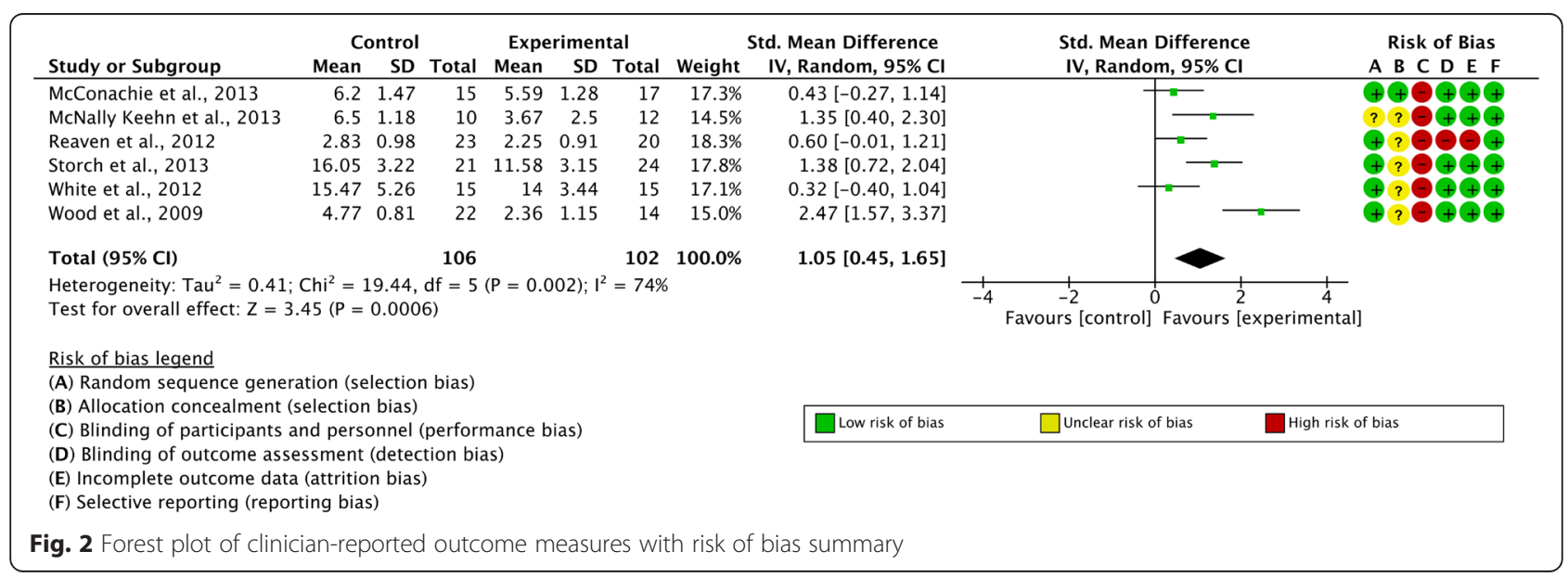




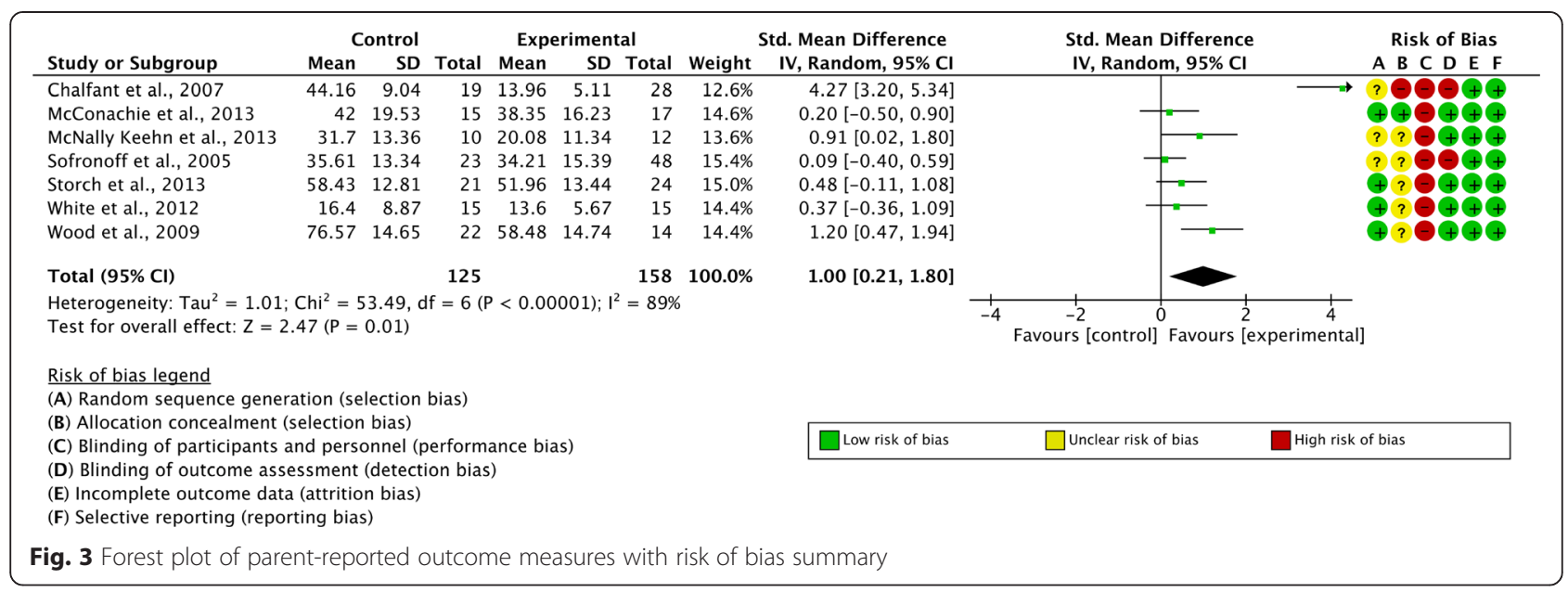

\section{Follow-up data}

McConachie et al. [37], McNally Keehn et al. [38], Sofronoff et al. [32], Storch et al. [29], and Sung et al. [40] reported follow-up data. The follow-up results were obtained between 6 weeks and 6 months after the end of the intervention. In three studies, there were only followup data available for the intervention condition since it was considered unethical to withhold treatment from the WL/TAU group. Therefore, only follow-up data from the intervention groups were examined in this review. The results in all five studies showed no statistically significant $(\mathrm{p}<0.05)$ difference between the post-treatment and follow-up scores for any of the outcome measures. Although the sample of studies that reported follow-up data was small, the results indicate that the positive effects of the intervention were maintained for some months after the final session.

\section{Discussion}

\section{Summary of evidence}

This meta-analysis aimed to investigate the effectiveness of psychosocial interventions for reducing anxiety in children and adolescents with ASD. Clinician- and parent-reported outcome measures showed that psychosocial interventions were superior to WL/TAU control conditions at posttreatment. In the parent-reported outcome measures category, the SMD from Chalfant et al. [30] was identified as an outlier. Although the summary estimate for parentreported outcome measures decreased following removal of this study, the post-treatment difference between the experimental and control groups remained significant. It should also be noted that Chalfant et al. [30] was rated as having a high risk of bias in multiple domains of the risk of bias assessment due to inadequate random sequence generation, allocation concealment, and blinding of participants, personnel and outcome assessment. For self-reported outcome measures, the difference between experimental and WL/TAU groups at post-treatment failed to reach significance. The subgroup analysis used to compare individual and group delivery of treatment showed that individual + /group therapy was more effective than group treatment alone, particularly for clinician-reported outcome measures. The results from this meta-analysis indicate that the evidence for using psychosocial interventions to manage

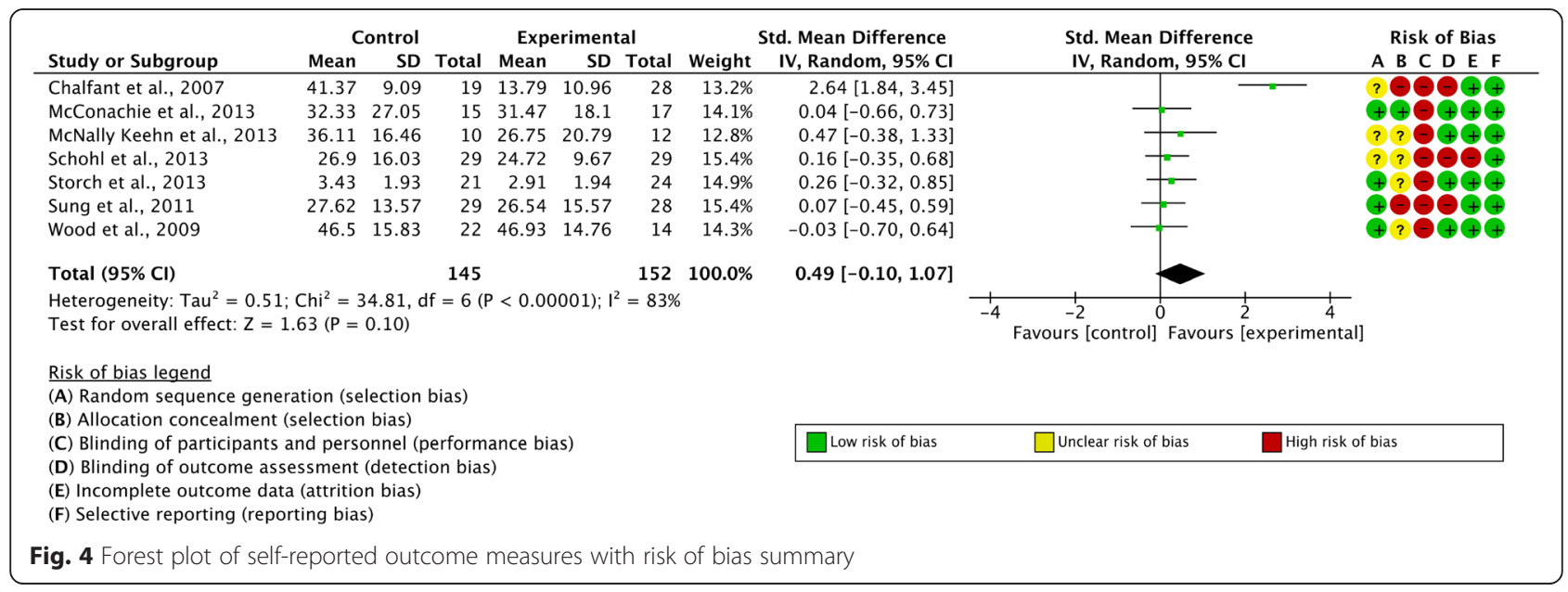


anxiety in ASD youth is fairly robust, but that the degree of effect differs across anxiety informants.

\section{Comparison of results to current literature}

A meta-analysis of RCTs investigating the effectiveness of $\mathrm{CBT}$ as a treatment for anxiety disorders in children and adolescents with ASD was published by Sukhodolsky et al. shortly after the study design for the present review had been established [45]. Sukhodolsky et al. reported a treatment effect of 1.21 (95\% CI 0.50, 1.97) for clinicianreported outcome measures, 1.19 (95\% CI 0.23, 2.14) for parent-reported outcome measures and 0.68 (95 \% CI $-0.17,1.54)$ for self-reported outcome measures. In addition to the studies included in the meta-analysis conducted by Sukhodolsky et al., the present study analysed two supplementary studies - one that was published in late 2013 [37] and one that used a social skills intervention rather than CBT [43]. The addition of these studies consistently reduced the overall SMD and narrowed the $95 \% \mathrm{CI}$, which may indicate that the treatment effect reported by Sukhodolsky et al. may have been overestimated.

\section{Treatment modality}

CBT modified for children and adolescents with ASD was the primary intervention modality studied in this meta-analysis. However, the search was extended to other types of psychosocial interventions since some of these have been shown to be as effective as CBT in ASD youth $[14,40]$. The only other type of psychosocial intervention that was identified in the search was a social skills intervention. The association between social disability and anxiety in ASD youth seems to be bidirectional. A higher IQ and greater social impairment has been shown to be associated with more severe anxiety symptoms, potentially due to the fact that individuals with higher IQ are more aware of their social deficits [23]. On the other hand, anxiety disorders can increase social isolation and disability [15]. Components of social skills interventions are essential as part of any psychosocial intervention aimed at ASD youth and a social skills approach to managing anxiety in ASD youth was therefore considered valid for inclusion in this metaanalysis.

Although psychosocial interventions seem to be effective in reducing anxiety compared to WL/TAU control conditions, the literature involving an active control is limited. Sung et al. [40] compared the effectiveness of CBT and a social recreational group and found no significant difference between the interventions and active control conditions at post-treatment and at 3- and 6-month follow-up. Russell et al. [14] also failed to detect a significant difference between the effectiveness of CBT and an anxiety management intervention on OCD symptoms in adults with ASD. Neither of these studies included a WL
/TAU condition. Although these studies indicate that a variety of psychosocial interventions may be equally effective in reducing anxiety symptoms in the paediatric ASD population, further research with more homogenous samples and multiple treatment arms will be necessary to fully establish the most effective treatment modalities.

\section{Individual versus group intervention}

Psychosocial interventions for ASD youth can be delivered in a variety of formats. Studies have been conducted using interventions in a group or individual format (or a combination of the two), but no study has yet compared these delivery methods against one another [6]. Individual therapy may be more flexible and allow treatment to be designed according to the individual's needs. Group therapy, on the other hand, may be beneficial in terms of peer support and sharing of experiences. The results from the subgroup analysis performed in this meta-analysis indicate that individual +/- group therapy is more beneficial than group therapy alone. For clinician-reported outcome measures, there was a significant difference between intervention and control conditions at post-treatment for both individual and group interventions. However, the summary estimate was significantly higher for the studies that used individual therapy only. For parent-reported outcome measures, the difference between intervention and control conditions was significant in those studies that used individual +/- group therapy. In contrast, in the studies that used group therapy only, the difference between intervention and control conditions failed to reach significance.

\section{Modifications}

Adapting psychosocial intervention programs to the needs of children and adolescents with ASD may improve the delivery of and response to treatment [46]. These modifications aim to minimise potential barriers that may limit the efficacy of treatment, including reduced ToM abilities, cognitive inflexibility, executive function deficits and concrete thinking [47]. The modification trends for CBT programs include the use of visual aids, incorporation of childspecific interests into the intervention, using highly structured sessions, and having a flexible number and length of sessions [46, 47].

Parental involvement in psychosocial interventions aimed at reducing anxiety in the paediatric population has been shown to positively affect treatment outcome in both typically developing children [48] and children with Asperger syndrome [41, 49]. Further studies have suggested that parenting and family factors, such as family accommodation, are associated with treatment outcomes $[14,30]$. It is important to consider the potential benefits of parental engagement in therapy targeted at the ASD population. Firstly, if parents are taught to become co-therapists, there may be reinforcement and 
generalisation of the taught skills in the home environment [32]. Secondly, involvement of parents may reduce parental anxiety and provide the necessary communication and coping skills to reduce the child's anxiety [40].

\section{Self-reported outcome measures}

Self-reported outcome measures are used as they are thought to provide reliable information about an individual's health and illness [50]. The use of self-reported measures in the paediatric population has become increasingly common. However, research of its efficacy is lacking [51]. In this review, parent- and clinician-reported outcome measures showed a greater treatment effect than selfreported measures which failed to reach significance. This finding mirrors results from recent studies of multiple informant agreement on anxiety measures in typically developing children [16] and children with ASD [52].

The reporting trends of different anxiety informants may reflect an actual difference in the perceived effects of the treatment between clinicians, parents and children. However, this inconsistency may be caused by other factors, which makes the use of self-reported outcome assessment questionable in paediatric populations. Children may lack the general cognitive abilities, self-awareness and understanding of health-related concepts to accurately report these types of outcome measures [53]. Furthermore, there is a general lack of understanding of how heath and illness perceptions are expressed by children at different stages of development [54].

In the paediatric ASD population, the use of self-reported measures can be especially challenging [11]. A proportion of the ASD population do not have the necessary communication and cognitive skills to conceptualise their thoughts, emotions and behaviours, as well as identify internal states such as worry and fear [11, 49]. Furthermore, individuals with ASD may not be able to distinguish between their feelings of anxiety from their experience of core ASD symptoms [7]. The anxiety symptoms may therefore be reported inaccurately. Measures of anxiety reported by primary caregivers are often considered more reliable in ASD youth [49]. However, if the child lacks expressive language skills, even caregivers may struggle to separate anxiety and ASD symptomology [11].

\section{Choice of outcome measures}

The presentation of anxiety in the paediatric ASD population is fundamentally different from the anxiety seen in typically developing children and there is a general lack of means to separate anxiety from core ASD symptomology [10]. Therefore, outcome measure tools developed to measure anxiety in typically developing children may not be adequate at capturing the unique nature of anxiety in an ASD population. Furthermore, the definition of a successful outcome in the anxious ASD population may include components that are not relevant for typically developing children, such as social and communication skills, and level of participation [11].

All the outcome measures selected for this review were developed to measure anxiety in typically developing children. There is some evidence that SCAS-C/P, SCARED-C/P, CASI, MASC-P, PARS and ADIS-C/P can be used to accurately measure anxiety in ASD. There is, however, some disagreement between studies regarding which instruments have the most robust measurement properties in the paediatric ASD population [10, 11]. Validated and sensitive instruments modified for use in children and adolescents with ASD will be necessary to improve comparability between study results as well as progress in treatment development [11]. However, until further psychometric research is carried out, the measure of anxiety in children and adolescents with ASD will rely on instruments developed for typically developing children.

\section{Future research}

Future research with larger sample groups and extended follow-up will be necessary to determine the precise effectiveness of psychosocial interventions for reducing anxiety in the ASD youth. Additional qualitative studies as well as the use of active control groups will be necessary to understand the specific components of psychosocial interventions that are most effective. More experience is required to establish empirically validated treatment manuals for use specifically in children and adolescents with ASD and find ways in which these manuals can be modified for different developmental stages. Future research will also have to ascertain how psychosocial interventions can be modified for lower functioning children and adolescents with ASD. Finally, further development of outcome measures will be essential to produce more reliable results.

\section{Limitations}

The results of this review may not be generalisable to the paediatric ASD population due to small samples, exclusion of the lower functioning subsets of the spectrum as well as limited representation of females and ethnic minorities. Although blinding of participants, personnel and most outcome assessments was not feasible, this lack of blinding may bias the results (perhaps due to wishful thinking and social pressure). It should also be noted that the participants in these studies were selfselected and therefore could have been drawn from an unusually motivated population.

The main limitation of this review was the inclusion of a relatively small number of studies due to the limited research in this area. This made it impossible to statistically analyse certain aspects of the data, including publication bias. Further limitations included clinical and 
methodological variability between studies. This variability made it impossible to conduct meaningful subgroup analyses to assess the potential effects of age, anxiety diagnoses, parental involvement and other factors on the treatment effect. In addition, there was a lack of studies in languages other than English. Finally, although data extraction and study analysis was conducted by two independent reviewers using a well validated and structured manual, there was still a certain level of subjectivity to the review process.

\section{Conclusion}

This meta-analysis aimed to systematically evaluate and summarise the evidence for using psychosocial interventions to manage anxiety in children and adolescents with ASD. Clinician- and parent-reported outcome measures showed that psychosocial interventions were superior to WL/TAU control conditions at post-treatment and individual therapy seemed to be more effective than group treatment. For self-reported outcome measures, the difference between experimental and WL/TAU groups at posttreatment failed to reach significance. However, more methodologically rigorous research will be necessary to ascertain the precise potential of psychosocial interventions to reduce anxiety in the paediatric ASD population.

\section{Abbreviations \\ ADIS-C/P: Anxiety Disorders Interview Schedule - Child/Parent version; ADOS: Autism Diagnostic Observation Schedule; AS: Asperger syndrome; ASD: Autism spectrum disorder; CASI-Anx: Childhood Anxiety Sensitivity Index - Anxiety; CBT: Cognitive behavioural therapy (CBT); CCDEF: Cochrane Collaboration Data Extraction Form; HFAD: High-Functioning Autistic Disorder; MASC-C/P: Multidimensional Anxiety Scale for Children - Child/Parent version; OCD: Obsessive compulsive disorder; PARS: Pediatric Anxiety Rating Scale; RCMAS: Revised Children's Manifest Anxiety Scale; RCT: Randomised Control Trial; SCAS-C/P: Spence Children's Anxiety Scale - Child/Parent version; SIAS: Social Interaction Anxiety Scale; SMD: Standardised mean difference; TAU: Treatment-as-usual; ToM: Theory of Mind; WL: Waitlist.}

\section{Competing interests}

The authors declare that they have no competing interests.

\section{Authors' contributions}

$A K, A R$ and $C M$ participated in the design of the meta-analysis. AK and AR performed the study selection and data collection. AK carried out the data analysis and wrote the manuscript under supervision of AR and CM. All authors read and approved the final manuscript.

Received: 17 December 2014 Accepted: 8 June 2015

Published online: 20 June 2015

\section{References}

1. Wing L, Gould J. Severe impairments of social interaction and associated abnormalities in children: epidemiology and classification. J Autism Dev Disord. 1979:9(1):11-29.

2. American Psychiatric Association. Diagnostic and Statistical Manual of Mental Disorders. 5th ed. Arlington: American Psychiatric Association; 2013.

3. Baird G, Simonoff E, Pickles A, Chandler S, Loucas T, Meldrum D, et al. Prevalence of disorders of the autism spectrum in a population cohort of children in South Thames: the Special Needs and Autism Project (SNAP). The Lancet. 2006;368(9531):210-5.

4. National Institute for Health and Care Excellence (NICE). Autism: The management and support of children and young people on the autism spectrum. Nice clinical guideline 170. https://www.nice.org.uk/guidance/ cg170/resources/guidance-autism-pdf (2013). Accessed 10 Dec 2014.
5. Skokauskas N, Gallagher L. Mental health aspects of autistic spectrum disorders in children. J Intellect Disabil Res. 2012;56(3):248-57.

6. White SW, Oswald D, Ollendick T, Scahill L. Anxiety in children and adolescents with autism spectrum disorders. Clin Psychol Rev. 2009:29:216-29.

7. Costello E, Egger HL, Angold A. The developmental epidemiology of anxiety disorders: Phenomenology, prevalence, and comorbidity. Child Adolesc Psychiatr Clin N Am. 2005;14:631-48.

8. Van Steensel FJ, Bögels SM, Perrin S. Anxiety disorders in children and adolescents with autistic spectrum disorders: a meta-analysis. Clin Child Fam Psychol Rev. 2011;14:302-17.

9. Kerns CM, Kendall PC. The Presentation and Classification of Anxiety in Autism Spectrum Disorder. Clin Psychol Sci Pract. 2012;19(4):323-47.

10. Wigham S, McConachie H. Systematic Review of the Properties of Tools Used to Measure Outcomes in Anxiety Intervention Studies for Children with Autism Spectrum Disorder. Plos One. 2014;9(1):1-17.

11. Lecavalier L, Wood JJ, Halladay AK, Jones NE, Aman MG, Cook EH, et al. Measuring Anxiety as a Treatment Endpoint in Youth with Autism Spectrum Disorder. J Autism Dev Disord. 2014;44(5):1128-43.

12. Wood JJ, Gadow KD. Exploring the Nature and Function of Anxiety in Youth with Autism Spectrum Disorders. Clin Psychol Sci Pract. 2010;17(4):281-92.

13. Simonoff E, Pickles A, Charman T, Chandler S, Loucas T, Baird G. Psychiatric disorders in children with Autism Spectrum Disorders: prevalence, comorbidity, and associated factors in a population-derived sample. J Am Acad Child Adolesc Psychiatry. 2008;47(8):921-9.

14. Russell AJ, Jassi A, Fullana MA, Mack H, Johnston K, Heyman I, et al. Cognitive Behavior Therapy for Comorbid Obsessive-Compulsive Disorder in High-Functioning Autism Spectrum Disorders: A Randomized Controlled Trial. Depress Anxiety. 2013;30(8):697-708.

15. Woods AG, Mahdavi E, Ryan JP. Treating clients with Asperger's syndrome and autism. Child Adolesc Psychiatry Ment Health. 2013;7(32):1-8.

16. James AC, James G, Cowdrey FA, Soler A, Choke A. Cognitive behavioural therapy for anxiety disorders in children and adolescents (Review). Cochrane Database Syst Rev. 2013;6:1-104.

17. Paul R, Orlovski SM, Marcinko HC, Volkmar F. Conversational Behaviors in Youth with High-functioning ASD and Asperger Syndrome. J Autism Dev Disord. 2009;39(1):115

18. Baron-Cohen, S. Theory of mind and autism: A review. In International review of research in mental retardation: Autism. Edited by Glidden LM. San Diego: Academic; 2001. p.169-184.

19. Dahlgren S, Sandberg AD, Hjelmquist E. The non-specificity of theory of mind deficits: Evidence from children with communicative disabilities. Eur J Cogn Psychol. 2003;15:129-55.

20. Liberati A, Altman DG, Tetzlaff J, Mulrow C, Gotzsche PC, loannidis JPA, et al. The PRISMA Statement for Reporting Systematic Reviews and Meta-Analyses of Studies That Evaluate Health Care Interventions: Explanation and Elaboration. Plos Med. 2009;6(7):1-29.

21. Higgins JPT, Green S (editors). Cochrane Handbook for Systematic Reviews of Interventions Version 5.1.0. [http://handbook.cochrane.org/].

22. Silverman WK, Albano AM. Anxiety Disorders Interview Schedule for DSM-IV, Child Version. New York: Oxford University Press; 1996.

23. RUPP Anxiety Study Group. The Pediatric Anxiety Rating Scale (PARS): development and psychometric properties. J Am Acad Child Adolesc Psychiatry. 2002;41(9):1061-9.

24. Sukhodolsky DG, Scahill L, Gadow KD, Arnold LE, Aman MG, McDougle CJ, et al. Parent-rated anxiety symptoms in children with pervasive developmental disorders: frequency and association with core autism symptoms and cognitive functioning. J Abnorm Child Psychol. 2008;36(1):117-28.

25. Spence SH. A measure of anxiety symptoms among children. Behav Res Ther. 1998;36(5):545-66.

26. March JS, Parker JD, Sullivan K, Stallings P, Conners CK. The Multidimensional Anxiety Scale for Children (MASC): factor structure, reliability, and validity. J Am Acad Child Adolesc Psychiatry. 1997;36(4):554-65.

27. Reynolds CR, Richmond BO. What I think and feel: a revised measure of children's manifest anxiety. J Abnorm Child Psychol. 1978;6(2):271-80.

28. Mattick RP, Clarke JC. Development and validation of measures of social phobia scrutiny fear and social interaction anxiety. Behav Res Ther. 1998;36:455-70.

29. Storch EA, Arnold EB, Lewin AB. The Effect of Cognitive-Behavioral Therapy Versus Treatment as Usual for Anxiety in Children With Autism Spectrum Disorders: A Randomized, Controlled Trial. J Am Acad Child Adolesc Psychiatry. 2013;52(2):132-42. 
30. Chalfant AM, Rapee R, Carroll L. Treating Anxiety Disorders in Children with High Functioning Autism Spectrum Disorders: A Controlled Trial. J Autism Dev Disord. 2007;37:1842-57.

31. Cohen J. Statistical Power Analysis in the Behavioral Sciences. 2nd ed. Hillsdale: Lawrence Erlbaum Associates, Inc; 1988.

32. Sofronoff $K$, Attwood T, Hinton S. A randomised controlled trial of a CBT intervention for anxiety in children with Asperger syndrome. J Child Psychol Psychiatry. 2005;46(11):1152-60.

33. Higgins JPT, Thompson SG. Quantifying heterogeneity in a meta-analysis Stat Med. 2002:21(11):1539-58.

34. DerSimonian R, Laird N. Meta-analysis in clinical trials. Control Clin Trials. 1986;7:177-88.

35. The Cochrane Collaboration: Review Manager (RevMan) Version 5.1 [Computer program]. Copenhagen; 2011.

36. Macaskill P, Walter SD, Irwig L. A comparison of methods to detect publication bias in meta-analysis. Stat Med. 2001;20:641-54.

37. McConachie H, McLaughlin E, Grahame V. Group therapy for anxiety in children with autism spectrum disorder. Autism. 2013. doi:10.1177/ 1362361313488839.

38. McNally Keehn RH, Brown MZ, Lincoln AJ, Chavira DA. The Coping Cat Program for Children with Anxiety and Autism Spectrum Disorder: A Pilot Randomized Controlled Trial. J Autism Dev Disord. 2013:43:57-67.

39. Reaven J, Blakeley-Smith A, Culhane-Shelburne K, Hepburn S. Group cognitive behavior therapy for children with high-functioning autism spectrum disorders and anxiety: a randomized trial. J Child Psychol Psychiatry. 2012;53(4):410-9.

40. Sung M, Ooi YP, Goh TJ. Effects of Cognitive-Behavioral Therapy on Anxiety in Children with Autism Spectrum Disorders: A Randomized Controlled Trial. Child Psychiatry Hum Dev. 2011:42:634-49.

41. White S, Ollendick T, Albano AM. Randomized Controlled Trial. Multimodal Anxiety and Social Skill Intervention for Adolescents with Autism Spectrum Disorder. J Autism Dev Disord. 2013:43:382-94.

42. Wood JJ, Drahota A, Sze K, Har K, Chiu A, Langer DA. Cognitive behavioral therapy for anxiety in children with autism spectrum disorders: a randomized, controlled trial. J Child Psychol Psychiatry. 2009;50(3):224-34.

43. Schohl KA, Van Hecke AV, Meyer Carson A, Dolan B, Karst J, Stevens S. A Replication and Extension of the PEERS Intervention: Examining Effects on Social Skills and Social Anxiety in Adolescents with Autism Spectrum Disorders. J Autism Dev Disord. 2014;44(3):532-45.

44. Lord C, Rutter M, DiLavore P, Risi S, Gotham K, Bishop SL. Autism Diagnostic Observation Schedule Manual. Los Angeles: Western Psychological Services; 1999.

45. Sukhodolsky DG, Bloch MH, Panza KE, Reichow B. Cognitive-Behavioral Therapy for Anxiety in Children With High-Functioning Autism: A meta-analysis. Pediatrics. 2013;132(5):1341-50.

46. Moree BN, Davis TE. Cognitive-behavioral therapy for anxiety in children diagnosed with autism spectrum disorders: Modification trends. Res Autism Spect Dis. 2010;4(3):346-54.

47. Scattone D, Mong M. Cognitive Behavior Therapy in the Treatment of Anxiety for Adolescnets and Adults with Autism Spectrum Disorders. Psychol Schools. 2013;50(9):923-35.

48. Khanna MS, Kendall PC. Exploring the role of parent training in the treatment of childhood anxiety. J Consult Clin Psychol. 2009:77:981-6.

49. Russell E, Sofronoff K. Anxiety and social worries in children with Asperger syndrome. Aust N Z J Psychiatry. 2005;39:633-8.

50. DeCivita $M$, Reiger D, Alamgir AH, Anis AH, FitzGerald MJ, Marra CA Evaluating health-related quality-of-life studies in paediatric populations: some conceptual, methodological and developmental considerations and recent applications. Pharmacoeconomics. 2005;23(7):659-85.

51. Bevans KB, Riley AW, Moon JH, Forrest CB. Conceptual and methodological advances in child-reported outcomes measurement. Expert Rev Pharmacoecon Outcomes Res. 2010;10(4):385-96.

52. Storch EA, Ehrenreich May J, Wood JJ, Jones AM, De Nadai AS, Lewin AB, et a Multiple informant agreement on the anxiety disorders interview schedule in youth with autism spectrum disorders. J Child Adolesc Psychopharmacol. 2012:22(4):292-9.

53. Bevans K, Forrest CB. The reliability and validity of children's self-reported health. In Economic Evaluation of Child Health. Edited by Ungar W. New York: Oxford University Press; 2010.

54. Forrest CB, Simpson L, Clancy C. Child health services research: challenges and opportunities. JAMA 1997:22:1787-93.

\section{Submit your next manuscript to BioMed Central and take full advantage of:}

- Convenient online submission

- Thorough peer review

- No space constraints or color figure charges

- Immediate publication on acceptance

- Inclusion in PubMed, CAS, Scopus and Google Scholar

- Research which is freely available for redistribution

Submit your manuscript at www.biomedcentral.com/submit 